\title{
Determination of the Population Structure of Fig Genotypes from Algeria and Turkey Using Inter Primer Binding Site-Retrotransposon and Simple Sequence Repeat Markers
}

\author{
Hakima Belttar1,2, Abdelouhab Yahia2, Seda Nemli33, Duygu Ates, Semih Erdogmus4, \\ Birgul Ertan', Sara Himour ${ }^{1,2}$, Serra Hepaksoy ${ }^{6}$, M. Bahattin Tanyolac ${ }^{4 *}$ \\ ${ }^{1}$ Department Biology and Plant Ecology, Faculty of Nature and Life Sciences, University Mentouri, Constantine, Algeria \\ ${ }^{2}$ Laboratory of Natural Sciences and Materials, Mila University Center, Algeria \\ ${ }^{3}$ Department of Genetics and Bioengineering, Gumushane University, Gumushane, Turkey \\ ${ }^{4}$ Department of Bioengineering, Ege University, Bornova-Izmir, Turkey \\ ${ }^{5}$ Ministry of Agriculture, Fig Research Institute, Aydın, Turkey \\ ${ }^{6}$ Department of Horticulture, Ege University, Izmir, Turkey \\ Email: *bahattin.tanyolac@ege.edu.tr
}

How to cite this paper: Belttar, H., Yahia, A., Nemli, S., Ates, D., Erdogmus, S., Ertan, B., Himour, S., Hepaksoy, S. and Tanyolac, M.B. (2017) Determination of the Population Structure of Fig Genotypes from Algeria and Turkey Using Inter Primer Binding Site-Retrotransposon and Simple Sequence Repeat Markers. Agricultural Sciences, 8, 1337-1357.

https://doi.org/10.4236/as.2017.812097

Received: October 27, 2017

Accepted: December 26, 2017

Published: December 29, 2017

Copyright $\odot 2017$ by authors and Scientific Research Publishing Inc. This work is licensed under the Creative Commons Attribution-NonCommercial International License (CC BY-NC 4.0). http://creativecommons.org/licenses/by-nc/4.0/ (c) (i) \& Open Access

\begin{abstract}
In order to identify the variation and estimate the genetic diversity among the fig (Ficus carica L.) genotypes collected from Algeria and Turkey, the genetic relationships between 86 genotypes were investigated using 23 inter primer binding sites (iPBS)-retrotransposon and 16 simple sequence repeat (SSR) primers. A total of 63 polymorphic bands for the iPBS-retrotransposon markers and 25 alleles for the SSR markers were identified with an average of 2.7 and 1.6 per primer, respectively. The average value of polymorphism information content (PIC) for the iPBS markers (0.73) was higher than that for the SSR markers (0.69). Applying the neighbor-joining method to the combined iPBS-retrotransposon and SSR data, the fig genotypes were clustered into two groups. The STRUCTURE software was used to determine the population structure. Among the genotypes studied, two populations $(K=2)$ were identified indicating a low diversity between the Algerian and Turkish varieties. Both types of markers were able to differentiate all the fig genotypes and were efficient in discriminating the closely related genotypes. Our data also showed that as a universal marker, iPBS-retrotransposon is a useful tool for the molecular characterization of fig genotypes.
\end{abstract}




\section{Keywords}

Ficus carica L., Inter Primer Binding Sites-Retrotransposon, Simple Sequence Repeat, Genetic Diversity, Population Structure

\section{Introduction}

The fig (Ficus carica L.) $(2 \mathrm{n}=26)$ belongs to the Moraceae family and consists of approximately 750 species of the genus Ficus [1]. The fig is one of the earliest fruit crops [2] that originated in western Asia and spread around the Mediterranean basin [3] including several areas in Turkey [4]. In Algeria, fig cultivation dates back to antiquity as an essential socio-economic activity that is associated with olive, grape, and citrus growing [5]. In 2014, the total global fig production was more than 1 million tons (1137.730 tons) and Turkey was the largest producer in the world with 300.282 tons in terms of planted area (49,464 ha) whereas Algeria ranked the second with a production of 128,620 tons and a cultivated area of 44,395 ha [6].

The diffusion of fig trees is based on the rooting of stem cuttings and this procedure has provided homonymy and synonymy, which has resulted in soma clonal variations and misidentification being common events in sexually cultivated species such as fig [7] [8]. Traditionally, the cultivar identification of fig trees mostly depends on phenotypic characteristics, such as the local geographical origin, color or size and the time that the fruit ripens, bringing about a confusion in nomenclature [9]. The interchange of plant material, advantages of the perturbation of certain traits through asexual propagation, and domestication existing over a long period of time also contribute to synonymy. In addition, the cultivar identification and their relationships maintain the confusion and uncertainty [10].

Recently, an efficient and universal molecular marker called inter-primer binding site (iPBS) has been developed by Kalendar et al. [11] as an alternative method to examine genetic diversity and relationships in plants [12] [13]. This method is highly reproducible due to its high rigor achieved by the annealing temperature and primer length. iPBS markers have been successfully utilized in genetic diversity analysis, phylogenetic studies, and clone identification [14]-[19]. However, to the best of our knowledge, these markers have never been used in the genetic diversity analysis of $F$. carica. Therefore, in this study, we employed iPBS-retrotransposon markers to detect genetic diversity in fig genotypes.

The polymorphisms of SSR and iPBS are generated via various mechanisms with different band patterns; therefore, these marker types provide information about the different aspects and properties of the genome to offer an insight into the whole population. With this in mind, the aim of this study was to identify the genetic background, structure, relationships, and diversity of fig cultivars distributed in Algeria and Turkey using iPBS and SSR markers. 


\section{Materials and Methods}

\subsection{Plant Material and DNA Extraction}

Eighty-six fig genotypes from different geographical origin of Turkey and Algeria were used in this study (Table 1).

The plant material consisted of young fresh leaves randomly sampled from adult trees. The fig leaves collected from Turkey were immediately frozen in liquid nitrogen and stored at $-80^{\circ} \mathrm{C}$ until use. For the collection of the Algerian samples, fig materials were extracted from lyophilized powdered young leaves of each genotype (National Center for Biotechnology Research "CRBt", Constantine). The total genomic DNA was isolated following the CTAB DNA isolation protocol described by Healey et al. [20] with minor modifications. For this purpose, $150 \mathrm{mg}$ grind leave sample was used for each genotype. Samples were prepared by adding $1500 \mu \mathrm{L}$ extraction buffer $(50 \mathrm{ml} 1 \mathrm{M}$ Tris, $25 \mathrm{ml} 0.5 \mathrm{M}$ EDTA, $150 \mathrm{ml} 5 \mathrm{M} \mathrm{NaCl}, 10 \mathrm{~g} \mathrm{CTAB}$, end volume $500 \mathrm{ml}$ ), then incubated at $65^{\circ} \mathrm{C}$ for 1 hour. After incubation, centrifuged at $8000 \mathrm{rpm}$ for $5 \mathrm{~min}$. and transferred the supernatant into a new microfuge tube and added an equal volume of chloroformisoamyl alcohol (24:1) and mixed gently by inversion for $5 \mathrm{~min}$. Then centrifuged at 11,000 rpm for $10 \mathrm{~min}$ and transferred the supernatant into a new microfuge tube again. RNAse $(10 \mu \mathrm{l})$ was added and incubated at $37^{\circ} \mathrm{C}$ for $15 \mathrm{~min}$. After incubation, equal volume of chloroform-isoamyl alcohol (24:1) was added and mixed gently by inversion for $5 \mathrm{~min}$. Then centrifuged at 11,000 rpm for 10 min and transferred the supernatant into a new microfuge tube again. Half volume of $\mathrm{NaCl}(5 \mathrm{M})$ and 3 volume of ice-cold ethanol (\%95) were added and stored at $-20^{\circ} \mathrm{C}$ for 1 hour. After this step, centrifuged at $9000 \mathrm{rpm}$ for $10 \mathrm{~min}$, discarded the supernatant and ethanol (\%70) was added and then centrifuged at $9000 \mathrm{rpm}$ for $10 \mathrm{~min}$ again. Supernatant was discarded and the pellet was airdried. Dried pellet was dissolved in $100 \mu \mathrm{TE}$ buffer and stored it at $4^{\circ} \mathrm{C}$ for immediate use or $-20^{\circ} \mathrm{C}$ for long-term storage. DNA concentration was inspected visually on agarose gel and also measured in a NanoDrop 1000 spectrophotometer (Thermo Sci. Co.).

\section{2. iPBS-Retrotransposon Markers Analysis}

A set of 32 iPBS primers were initially screened using both groups of samples to determine the polymorphism rank of the primers. A total of 23 primers, which produced polymorphic bands, were selected for the evaluation of genetic diversity [11]. The name, sequence, length, and annealing temperature of the primers are presented in Table 2.

The PCR was conducted in $20 \mu \mathrm{L}$ reaction mixtures, containing $5 \mathrm{ng}$ genomic DNA, $10 \times$ PCR buffer (Applied Biological Materials Inc.), $1.2 \mathrm{mM}$ dNTP (Thermo Fisher Scientific Inc.), primer (10 pmol), and 0.2 unit Taq DNA polymerase (Applied Biological Materials Inc.). PCR amplification was performed using an MJ research thermal cycler (DNA Engine DYAD; Bio-Rad, USA) starting with 
Table 1. List of Ficus carica genotypes collected from different locations in Algeria and Turkey.

\begin{tabular}{|c|c|c|c|c|c|c|c|}
\hline No (\#) & Location & Variety & Source & No (\#) & Location & Variety & Source \\
\hline 1 & Ege Univ., Izmir & Morgüz & $\mathrm{DH}^{\mathrm{a}}$ & 44 & Aydin & Sarı Zeybek & $\mathrm{FRI}^{\mathrm{b}}$ \\
\hline 2 & Ege Univ., Izmir & Sultan Selim & $\mathrm{DH}^{\mathrm{a}}$ & 45 & Aydin & 1088 Siyah Kış & $\mathrm{FRI}^{\mathrm{b}}$ \\
\hline 3 & Ege Univ., Izmir & Cicek Inciri & $\mathrm{DH}^{\mathrm{a}}$ & 46 & Aydin & 1082 Akcakim & FRI $^{\mathrm{b}}$ \\
\hline 4 & Ege Univ., Izmir & Umurbey & $\mathrm{DH}^{\mathrm{a}}$ & 47 & Aydin & 1008 Yeşilgüz & $\mathrm{FRI}^{\mathrm{b}}$ \\
\hline 5 & Ege Univ., Izmir & Kadota2 & $\mathrm{DH}^{\mathrm{a}}$ & 48 & Aydin & 1066 Yediveren & $\mathrm{FRI}^{\mathrm{b}}$ \\
\hline 6 & Ege Univ., Izmir & Kadotal & $\mathrm{DH}^{\mathrm{a}}$ & 49 & Aydin & 1019 Karabakunya & $\mathrm{FRI}^{\mathrm{b}}$ \\
\hline 7 & Ege Univ., Izmir & Beyaz Cicek & $\mathrm{DH}^{\mathrm{a}}$ & 50 & Aydin & 506 Beyaz Sultani & $\mathrm{FRI}^{\mathrm{b}}$ \\
\hline 8 & Ege Univ., Izmir & Siyah Cicek & $\mathrm{DH}^{\mathrm{a}}$ & 51 & Aydin & Darpak & $\mathrm{FRI}^{\mathrm{b}}$ \\
\hline 9 & Ege Univ., Izmir & Siyah İncir & $\mathrm{DH}^{\mathrm{a}}$ & 52 & Aydin & 407 Halebi & $\mathrm{FRI}^{\mathrm{b}}$ \\
\hline 10 & Ege Univ., Izmir & Akca & $\mathrm{DH}^{\mathrm{a}}$ & 53 & Aydin & 318 Mor Incir & $\mathrm{FRI}^{\mathrm{b}}$ \\
\hline 11 & Ege Univ., Izmir & Göklop & $\mathrm{DH}^{\mathrm{a}}$ & 54 & Skikda & Albo & ITAFV $^{c}$ \\
\hline 12 & Ege Univ., Izmir & Kara Yaprak & $\mathrm{DH}^{\mathrm{a}}$ & 55 & Skikda & Celeste & ITAFV $^{c}$ \\
\hline 13 & Ege Univ., Izmir & Bardakci & $\mathrm{DH}^{\mathrm{a}}$ & 56 & Skikda & Cavaliere & ITAFV $^{c}$ \\
\hline 14 & Ege Univ., Izmir & Bursa Siyahi & $\mathrm{DH}^{\mathrm{a}}$ & 57 & Skikda & Boule d'or & ITAFV $^{c}$ \\
\hline 15 & Ege Univ., Izmir & Sarilop & $\mathrm{DH}^{\mathrm{a}}$ & 58 & Skikda & Blanquette & ITAFV $^{c}$ \\
\hline 16 & Aydin & 403 Sultani & FRI $^{\mathrm{b}}$ & 59 & Skikda & Blak dourou & ITAFV $^{c}$ \\
\hline 17 & Aydin & 305 Mor Incir & FRI $^{\mathrm{b}}$ & 60 & Skikda & Bifer de tala amara & ITAFV $^{c}$ \\
\hline 18 & Aydin & 302 Mor Incir & FRI $^{\mathrm{b}}$ & 61 & Skikda & Bakor blanc & $\mathrm{ITAFV}^{\mathrm{c}}$ \\
\hline 19 & Aydin & 244 Kavak Patlican & FRI $^{\mathrm{b}}$ & 62 & Skikda & Avouacou & $\mathrm{ITAFV}^{\mathrm{c}}$ \\
\hline 20 & Aydin & 243 Susak & $\mathrm{FRI}^{\mathrm{b}}$ & 63 & Skikda & Alekak & $\mathrm{ITAFV}^{\mathrm{c}}$ \\
\hline 21 & Aydin & 232 Kocayemiş & $\mathrm{FRI}^{\mathrm{b}}$ & 64 & Skikda & Abiarous & ITAFV $^{c}$ \\
\hline 22 & Aydin & 235 Yediveren & $\mathrm{FRI}^{\mathrm{b}}$ & 65 & Skikda & Fraga & ITAFV $^{c}$ \\
\hline 23 & Aydin & 222 Kavak Yediveren & FRI $^{\mathrm{b}}$ & 66 & Skikda & Gentille & ITAFV $^{c}$ \\
\hline 24 & Aydin & 220 Dumanlıkara & FRI $^{\mathrm{b}}$ & 67 & Skikda & Hamri & ITAFV $^{c}$ \\
\hline 25 & Aydin & 216 Siyah Incir & $\mathrm{FRI}^{\mathrm{b}}$ & 68 & Skikda & Karout & $\mathrm{ITAFV}^{\mathrm{c}}$ \\
\hline 26 & Aydin & 212 Cicek Inciri & $\mathrm{FRI}^{\mathrm{b}}$ & 69 & Skikda & Roudane & ITAFV $^{c}$ \\
\hline 27 & Aydin & 1032 Deve Tabanı & $\mathrm{FRI}^{\mathrm{b}}$ & 70 & Skikda & Taranimt & ITAFV $^{c}$ \\
\hline 28 & Aydin & 210 Mor Incir & $\mathrm{FRI}^{\mathrm{b}}$ & 71 & Skikda & Tameriout & ITAFV $^{c}$ \\
\hline 29 & Aydin & 208 Siyah Incir & FRI $^{\mathrm{b}}$ & 72 & Skikda & Verbale & ITAFV $^{c}$ \\
\hline 30 & Aydin & 209 Mor Incir & $\mathrm{FRI}^{\mathrm{b}}$ & 73 & Skikda & Zreka & ITAFV $^{c}$ \\
\hline 31 & Aydin & 237 Bursa Siyahi & $\mathrm{FRI}^{\mathrm{b}}$ & 74 & Skikda & El fessi & ITAFV $^{c}$ \\
\hline 32 & Aydin & 256 Yediveren & $\mathrm{FRI}^{\mathrm{b}}$ & 75 & Skikda & Bezoul el khadem & ITAFV $^{c}$ \\
\hline 33 & Aydin & 1001 Göklop & FRI $^{\mathrm{b}}$ & 76 & Old city Mila & Shenoufkhia & $\mathrm{PO}^{\mathrm{d}}$ \\
\hline 34 & Aydin & 1010 Kara Yaprak & $\mathrm{FRI}^{\mathrm{b}}$ & 77 & Old city Mila & Soltani/ Soltania & $\mathrm{PO}^{\mathrm{d}}$ \\
\hline 35 & Aydin & 1106 Akgüz & FRI $^{\mathrm{b}}$ & 78 & Old city Mila & L'Alebia & $\mathrm{PO}^{\mathrm{d}}$ \\
\hline 36 & Aydin & 1018 Yediveren & FRI $^{\mathrm{b}}$ & 79 & Old city Mila & Bouzenouna & $\mathrm{PO}^{\mathrm{d}}$ \\
\hline
\end{tabular}




\section{Continued}

\begin{tabular}{|c|c|c|c|c|c|c|c|}
\hline 37 & Aydin & 1046 Mor Incir & $\mathrm{FRI}^{\mathrm{b}}$ & 80 & Old city Mila & Rekaib el Alma & $\mathrm{PO}^{\mathrm{d}}$ \\
\hline 38 & Aydin & 1004 Kuşadası Bardakcı & $\mathrm{FRI}^{\mathrm{b}}$ & 81 & Old city Mila & Bejaoui/Bejaouia & $\mathrm{PO}^{\mathrm{d}}$ \\
\hline 39 & Aydin & 1045 Mor Güz & $\mathrm{FRI}^{\mathrm{b}}$ & 82 & Old city Mila & Zerighy & $\mathrm{PO}^{\mathrm{d}}$ \\
\hline 40 & Aydin & 1002 Bardakc1 & $\mathrm{FRI}^{\mathrm{b}}$ & 83 & Old city Mila & El sefral & $\mathrm{PO}^{\mathrm{d}}$ \\
\hline 41 & Aydin & 1107 Kadota & $\mathrm{FRI}^{\mathrm{b}}$ & 84 & Old city Mila & El sefra2 & $\mathrm{PO}^{\mathrm{d}}$ \\
\hline 42 & Aydin & 1013 Beyaz Orak & $\mathrm{FRI}^{\mathrm{b}}$ & 85 & Old city Mila & Biferia & $\mathrm{PO}^{\mathrm{d}}$ \\
\hline 43 & Aydin & 1012 Siyah Orak & $\mathrm{FRI}^{\mathrm{b}}$ & 86 & Old city Mila & Dhokkar & $\mathrm{PO}^{\mathrm{d}}$ \\
\hline
\end{tabular}

$\mathrm{DH}^{\mathrm{a}}$ Department of Horticulture (Ege University, Izmir, Turkey), FRI ${ }^{\mathrm{b}}$ Fig Research Institute (Aydin, Turkey), ITAFV ${ }^{\mathrm{c}}$ Institut Technique de L'Arboriculture Fruitière de la Vigne (Skikda, Skikda, Algeria), PO ${ }^{\mathrm{d}}$ Private orchard (Old city Mila, Algeria).

Table 2. Genetic diversity information for 23 iPBS primers among 86 fig genotypes.

\begin{tabular}{|c|c|c|c|c|c|}
\hline iPBS primer name & Sequences & $\mathrm{nt}^{*}$ & $\operatorname{Tm}\left({ }^{\circ} \mathrm{C}\right)^{*}$ & Number of polymorphic bands & PIC \\
\hline 2076 & GCTCCGATGCCA & 12 & 50 & 3 & 0.74 \\
\hline 2079 & AGGTGGGCGCCA & 12 & 55 & 2 & 0.66 \\
\hline 2384 & GTAATGGGTCCA & 12 & 41 & 3 & 0.74 \\
\hline 2394 & GAGCCTAGGCCA & 12 & 48 & 2 & 0.99 \\
\hline 2075 & CTCATGATGCCA & 12 & 42 & 2 & 0.96 \\
\hline 2375 & TCGCATCAACCA & 12 & 45 & 1 & 0.99 \\
\hline 2379 & TCCAGAGATCCA & 12 & 41 & 1 & 0.05 \\
\hline 2380 & CAACCTGATCCA & 12 & 41 & 2 & 0.54 \\
\hline 2381 & GTCCATCTTCCA & 12 & 40 & 2 & 0.98 \\
\hline 2383 & GCATGGCCTCCA & 12 & 50 & 2 & 0.53 \\
\hline 2387 & GCGCAATACCCA & 12 & 47 & 2 & 0.98 \\
\hline 2388 & TTGGAAGACCCA & 12 & 43 & 6 & 0.96 \\
\hline 2393 & TACGGTACGCCA & 12 & 45 & 7 & 0.66 \\
\hline 2238 & ACCTGGCGTGCCA & 13 & 47 & 1 & 0.50 \\
\hline 2273 & GCTCATCATGCCA & 13 & 45 & 2 & 0.86 \\
\hline 2277 & GGCGATGATACCA & 13 & 47 & 6 & 0.65 \\
\hline 2229 & CGACCTGTTCTGATACCA & 18 & 48 & 2 & 0.70 \\
\hline 2238 & ACCTAGCTCATGATGCCA & 18 & 55 & 1 & 0.15 \\
\hline 2249 & AACCGACCTCTGATACCA & 18 & 47 & 5 & 0.83 \\
\hline 2251 & GAACAGGCGATGATACCA & 18 & 55 & 2 & 0.86 \\
\hline 2252 & TCATGGCTCATGATACCA & 18 & 45 & 1 & 0.99 \\
\hline 2228 & CATTGGCTCTTGATACCA & 18 & 52 & 5 & 0.89 \\
\hline \multirow[t]{3}{*}{2232} & AGAGAGGCTCGGATACCA & 18 & 43 & 3 & 0.55 \\
\hline & Total & & & 63 & \\
\hline & Mean & & & 2.7 & 0.73 \\
\hline
\end{tabular}

${ }^{*} \mathrm{Tm}\left({ }^{\circ} \mathrm{C}\right)$ : annealing temperature, nt: Length of primer. 
pre-denaturation at $94^{\circ} \mathrm{C}$ for $30 \mathrm{~s}$, followed by 35 cycles of denaturation at $94^{\circ} \mathrm{C}$ for $25 \mathrm{~s}$, annealing at appropriate temperature for $45 \mathrm{~s}$, and extension at $72^{\circ} \mathrm{C}$ for $60 \mathrm{~s}$ completed with the final extension at $72^{\circ} \mathrm{C}$ for $5 \mathrm{~min}$. The PCR products were analyzed on agarose gel and photographed using the G-box SYNGENE gel documentation system.

\subsection{SSR Markers Analysis}

The 34 SSR primers that were obtained from Khadari et al. [21], Giraldo et al. [22], Zavodna et al. [23], Ahmed et al. [24], and Bandelj et al. [25] were used for genotyping. Using a thermo cycler (MJ Research TM, Nevada, USA), PCR was performed with $20 \mu \mathrm{L}$ of reaction mixtures. The mixtures contained $5 \mathrm{ng}$ of genomic DNA, forward and reverse primers (20 pmol), $1 \mathrm{mM}$ dNTP, 10X PCR buffer, and 1 unit Taq DNA polymerase. The amplification was started at $94^{\circ} \mathrm{C}$ for $3 \mathrm{~min}$, followed by 40 cycles of $30 \mathrm{~s}$ at $94^{\circ} \mathrm{C}, 40 \mathrm{~s}$ at the annealing temperature, $30 \mathrm{~s}$ at $72^{\circ} \mathrm{C}$, and completed with a $5 \mathrm{~min}$ extension at $72^{\circ} \mathrm{C}$. The PCR products were separated on agarose gel and photographed under ultraviolet light for further analysis (SynGene GBox, MD, USA).

\subsection{Data Analysis}

The efficiency of iPBS and SSR markers in determining the genetic diversity of fig was evaluated by counting the reproducible and product bands and scoring them as present (1) or absent (0) for each genotype. Only clear and strong bands were recorded and used for further analysis. Polymorphism information content (PIC) values were obtained using the formula developed by Anderson et al. [26]: $\mathrm{PIC}=1-\Sigma \mathrm{Pi}^{2}$, where $\mathrm{P}_{\mathrm{i}}$ is the frequency of the $i$ th allele in the set of genotypes investigated. DNA markers showed an average value of PIC $>0.5$, which confirms that markers were highly informative [27].

The genetic distance between 86 fig genotypes was calculated according to Nei and Li's dissimilarity coefficient of NTSYS-pc (Numerical Taxonomy and Multivariate Analysis System, version 2.0) [28] for pairwise comparisons based on the proportion of shared bands produced by all primers. Using the $\mathrm{R}$ statistical software, a dendrogram was created based on the unweighted pair group method average (UPGMA) according to the similarities between the genotypes and a principal component analysis (PCA) was performed [29]. The results of the iPBS and SSR markers were obtained separately and combined for the overall genetic analysis.

The population structures of the genotypes were also investigated using a model-based clustering algorithm (STRUCTURE v.2.2) that genetically separates groups according to allele frequencies [30]. The number of hypothetical subpopulations $(\mathrm{K})$ was estimated by a continuous series of $\mathrm{K}$, from 1 to 10 , in 10 independents runs, applying the mixture and correlated allele frequencies. The program was executed using a burning period of 100,000 steps and 100,000 Monte Carlo Markov Chain (MCMC) interactions. To select the optimal value 
of $\mathrm{K}, \Delta \mathrm{K}$ values [31] were calculated using STRUCTURE HARVESTER [32]. The change in the log probability of data between successive $\mathrm{K}$ values obtained from the STRUCTURE output was used to determine the true number of subpopulations.

\section{Results}

\section{1. iPBS-Retrotransposon Markers Analysis}

Of the 35 iPBS primers screened, 3 (2074, 2237, and 2395) revealed no amplification while 9 iPBS primers $(2087,2222,2272,2298,2376,2389,2391,2392$, and 2415) showed a monomorphic banding pattern. The remaining 23 iPBS primers (16 12-13-nt long and 7 18-nt long) were unambiguous and resulted in reproducible amplification; therefore, these primers were selected for further analysis (Table 2). A representative banding pattern of 12 iPBS-retrotransposon primer showing polymorphisms on 3 genotypes (genotype 1,2 and 3) are shown in Figure 1. While all primers showed clear polymorphic banding pattern, primer iPBS2382 showed weak and not sharp banding pattern and this primer was eliminated from the analysis (Figure 1).

From the 23 iPBS primers, a total of 63 polymorphic bands were detected (Table 2). The number of polymorphic bands per primer ranged from 1 (iPBS primers 2238, 2252, 2270, 2375, and 2379) to 7 (2393). The highest PIC value (0.997) was obtained from iPBS primer 2252, and the lowest (0.046) from 2379

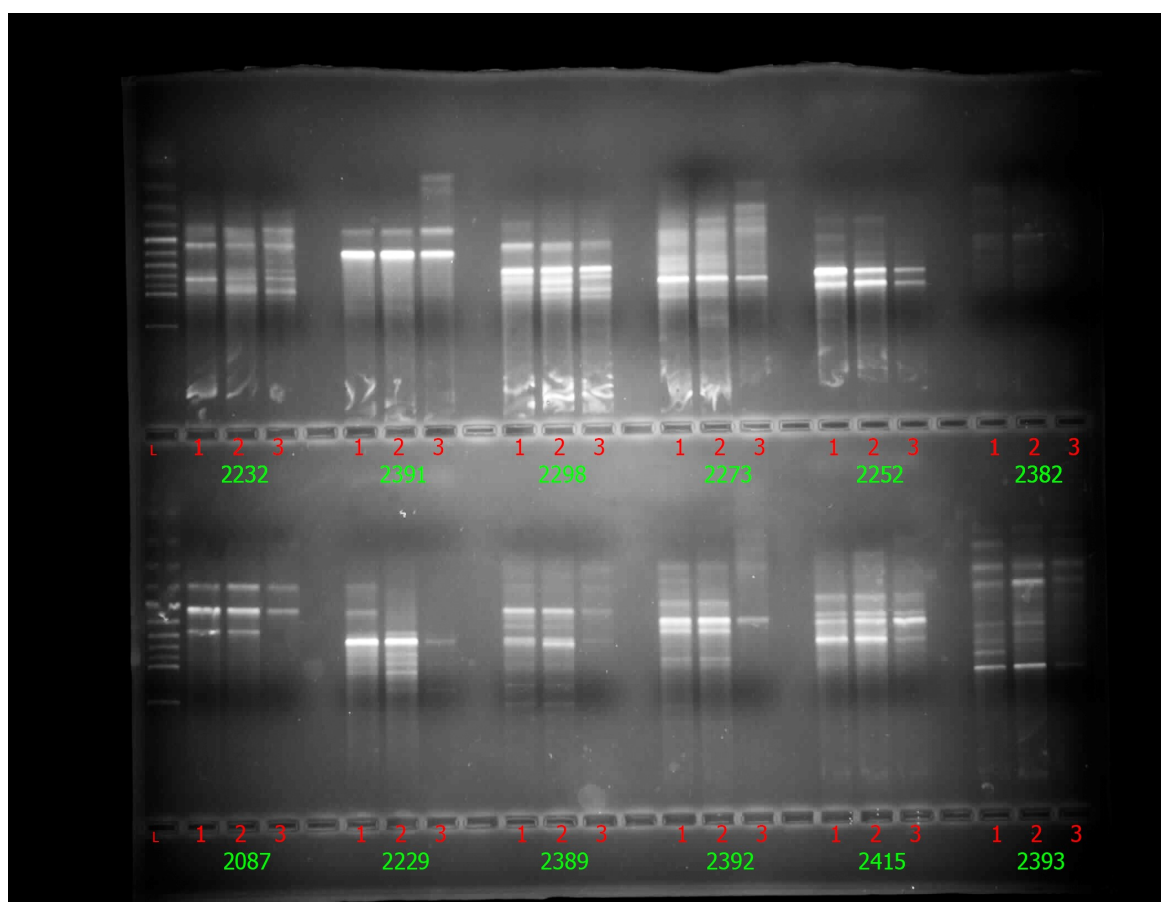

Figure 1. Amplification pattern of 12 iPBS-retrotransposon primers (iPBS2087, iPBS2229, iPBS2389, iPBS2392, iPBS2415, iPBS2393, iPBS2232, iPBS2391, iPBS2298, iPBS2273, iPBS2252, iPBS2382), showing polymorphism between the 3 genotypes (Genotype 1, 2 and 3); L, 100-bp ladder. 
ith an average of 0.73 (Table 2). The size of reproducible and scorable bands ranged from 100 to $900 \mathrm{bp}$.

\subsection{SSR Markers Analysis}

Among the 34 SSR primers screened, LMFC2, LMFC8, LMFC32, MFC9, LMFC25, FCUPO274, and Fsyc09 detected no polymorphism, and 11 primers produced monomorphic banding patterns (Fsyc04, LMFC24, LMFC34, LMFC35, LMFC37, LMFC38, LMFC36, LMFC28, and LMFC40). Therefore, these 18 primers were excluded from further analysis. The remaining 16 SSR primers were used to fingerprint all the genotypes. The total number of polymorphic bands was 25 alleles per locus ranging from 1 (MFC1, MFC11, LMFC20, LMFC21, LMFC22, LMFC26, LMFC27, LMFC30, FCUPO38-6, and FCUPO68-1) to 3 (LMFC31, FCUPO66-7, and MF4-70), with an average of 1.5 alleles per locus. The size of reproducible and scorable bands ranged from 100 to $1300 \mathrm{bp}$. The PIC values were found to vary between 0.16 (LMFC21) and 0.95 (LMFC22) with a mean of 0.56 . Fourteen SSR primers were classified as highly informative markers (PIC > 0.5).

\subsection{Data Analysis}

Genetic distances were calculated and three neighbor-joining trees were constructed using the dissimilarity matrix based on iPBS only, SSR only, and the combined data of iPBS and SSR. According to the iPBS-retrotransposon analysis, the highest genetic distance (0.90) was observed between the pair of genotypes \#83 (El sefra1) and \#84 (El sefra2) while the lowest value (0.00) was seen between \#56 (Cavaliere) and \#66 (Gentille). However, according to the SSR analysis, the highest genetic distance (0.95) was found between two pairs of genotypes; \#16 (403 Sultani) and \#67 (Hamri), and \#34 (1010 Kara Yaprak) and \#67 (Hamri) while the minimum genetic distance (0.00) was observed between \#83 (El sefra1) and \#84 (El sefra2). When we combined the iPBS and SSR data, the lowest values of genetic dissimilarity (0.00) were observed between the genotypes \#83 (El sefra1) and \#84 (El sefra2), indicating that these genotypes were highly distinct from each other. The dissimilarity value (0.95) demonstrated that the most closely related genotypes were \#50 (506 Beyaz Sultani) and \#57 (Boule d'or) as well as \#57 (Boule d'or) and \#85 (Biferia).

The genetic distance between the pairs of genotypes was used to perform a cluster analysis based on neighbor joining (Figures 2-4). The results of this analysis revealed that 86 fig genotypes formed two main groups of clusters based on the iPBS data. Groups 1 and 2 contained the major genotypes, which were further divided into two subgroups (Figure 2) consisting of 44 (shown in red) and 42 (green) genotypes, respectively. Similarly, using the SSR data, the 86 fig genotypes were divided into two main groups (Figure 3) with 49 (red) and 37 (green) genotypes, respectively. However, the genotypes within the groups were slightly different. The combined data also resulted in two main groups of genotypes (Figure 4) containing 53 (red) and 33 genotypes (green), respectively. The 


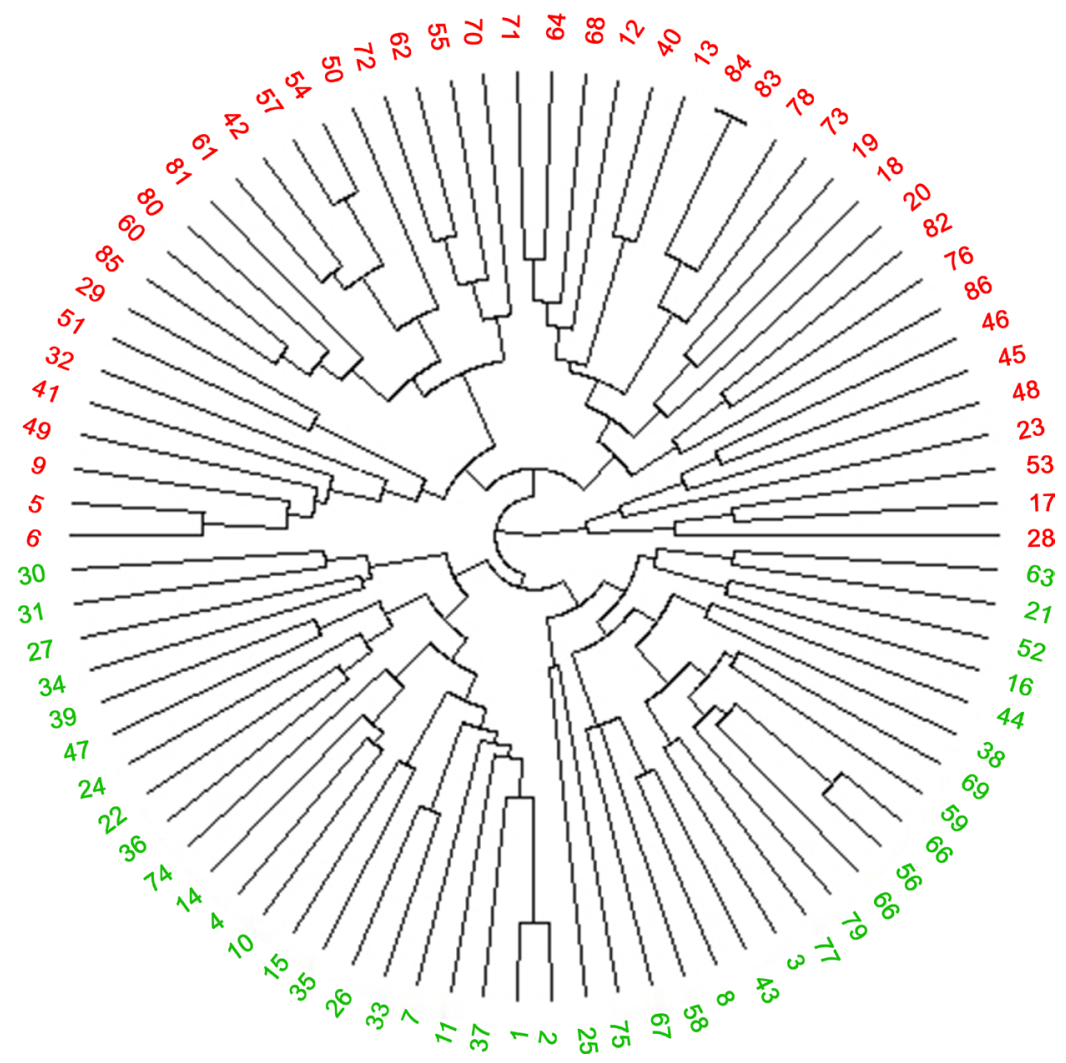

Figure 2. The UPGMA dendrogram of 86 fig genotypes generated with iPBS data.

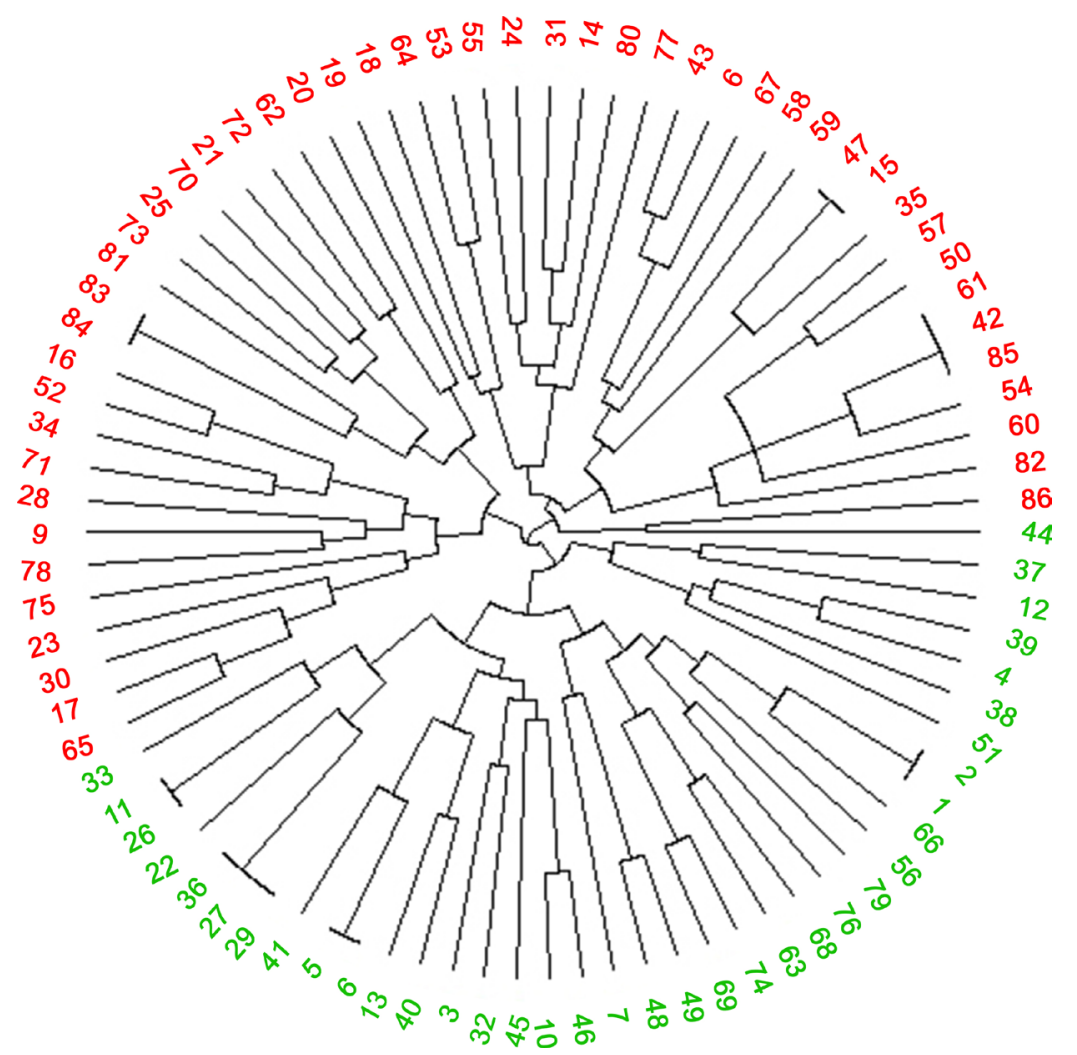

Figure 3. The UPGMA dendrogram of 86 fig genotypes generated with SSR data. 


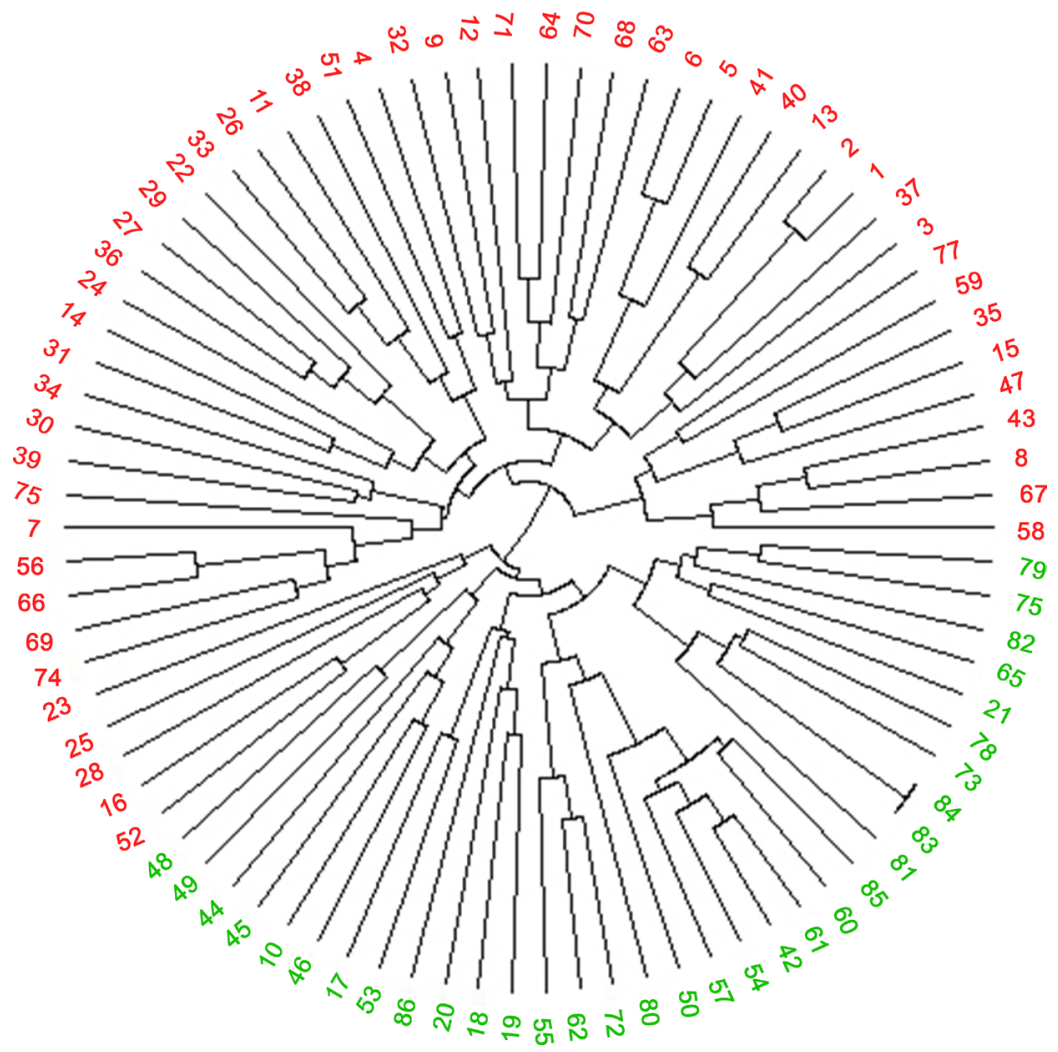

Figure 4. The UPGMA dendrogram of 86 fig genotypes generated with iPBS + SSR data.

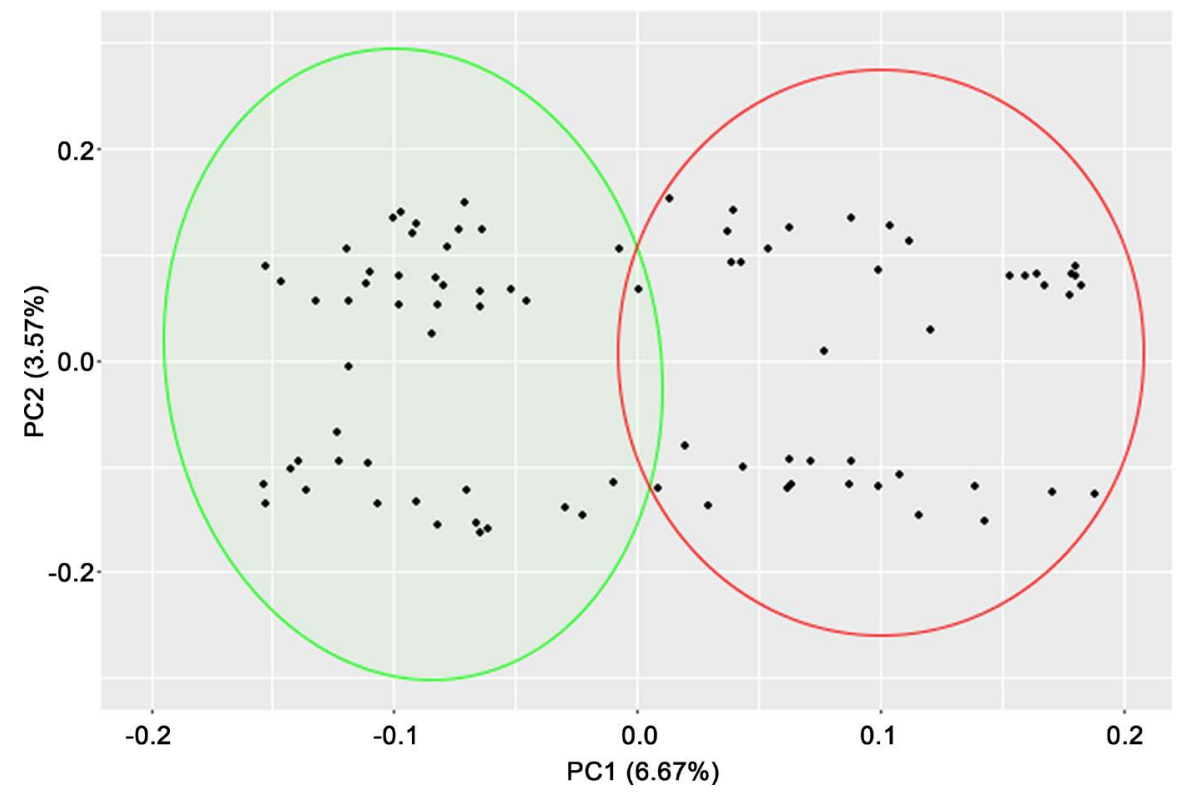

Figure 5. Results of PCA of 86 fig genotypes based on iPBS data.

grouping patterns of the genotypes in the combined analysis were found similar to those obtained from the separate analyses of the iPBS and SSR markers.

The PCA of the relative genetic distances between individual genotypes was used to investigate the pattern of variation (Figures 5-7). With this analysis, the 


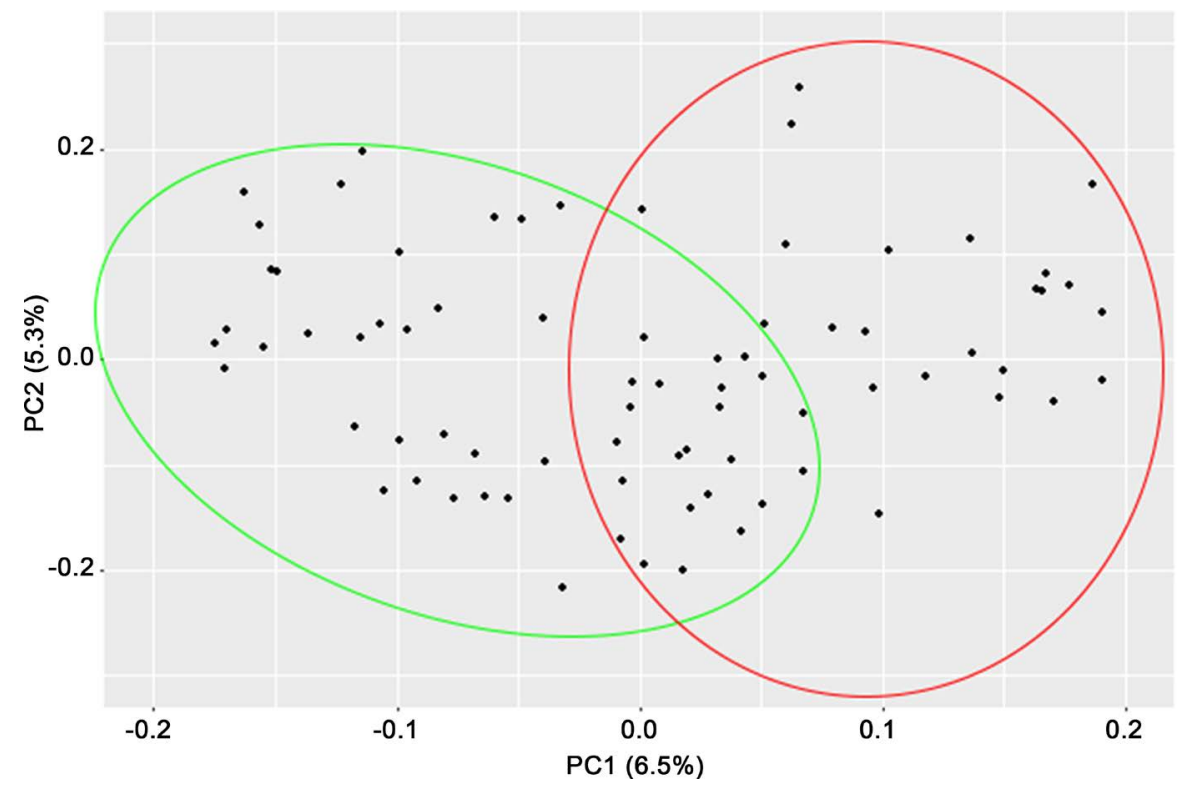

Figure 6. Results of PCA of 86 fig genotypes based on SSR data.

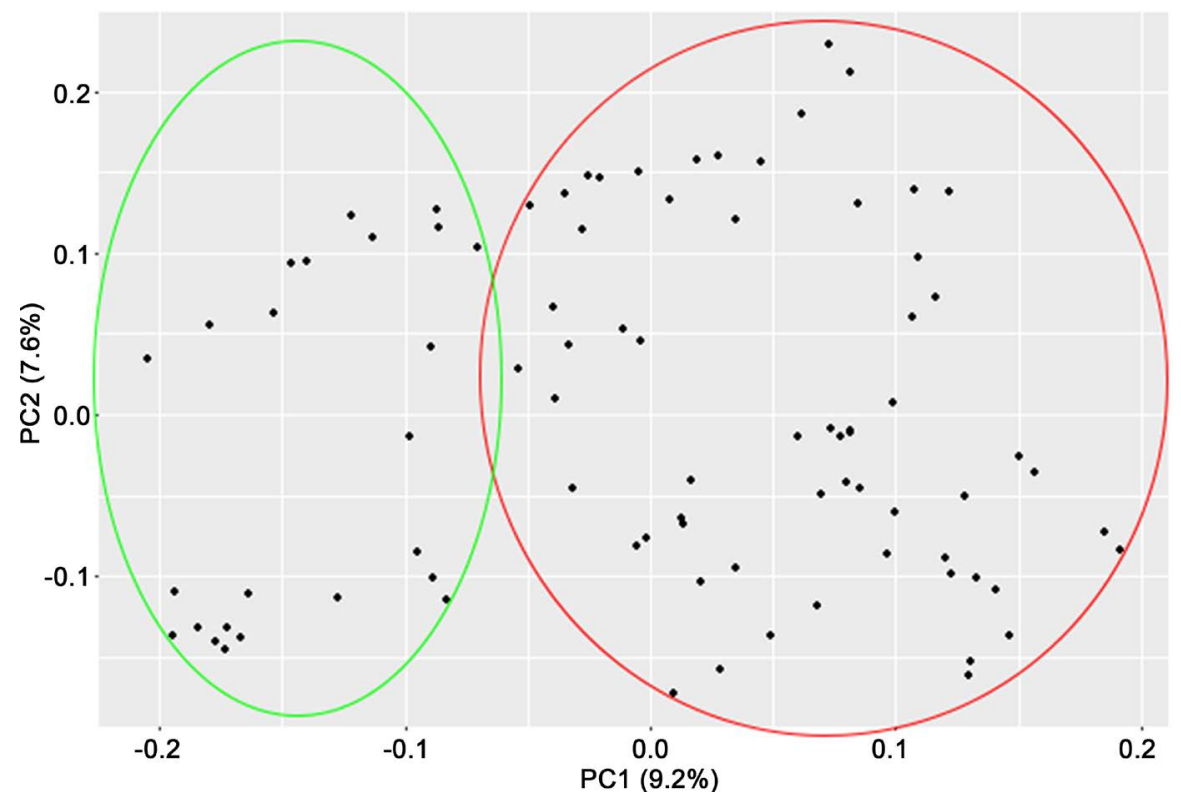

Figure 7. Results of PCA of 86 fig genotypes based on iPBS + SSR data.

clustering of fig genotypes was evaluated using 63 iPBS and 25 SSR polymorphism bands. According to the results of PCA, the genotypes were mainly divided into two groups with the two axes explaining only $6.7 \%$ and $3.7 \%$ of the molecular variation, respectively, and no apparent geographic structuring was identified using the iPBS markers (Figure 5). For the SSR data, the first two axes explained $11.8 \%$ of the total variation $(6.5 \%$ and $5.3 \%$ for the first and second coordinates, respectively) (Figure 6). Almost all the genotypes were plotted in two different dimensional plots, on the two top planes. Using the SSR and iPBS data, the PCA of 86 fig genotypes revealed that the first two principal coordinates 


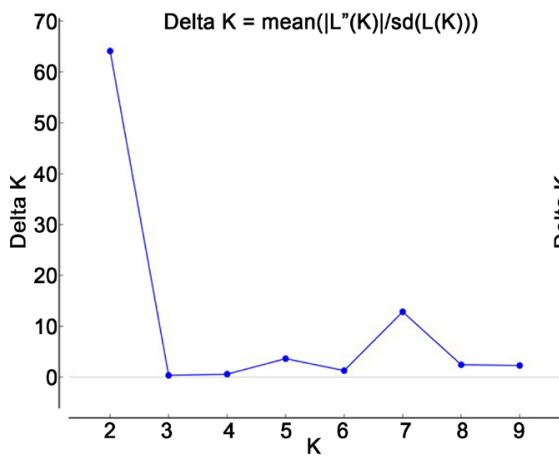

(a) iPBS

(PCA1 and PCA2) explained $16.8 \%$ of the total variability $9.2 \%$ and $7.6 \%$, respectively) (Figure 7).

The genetic structure of the whole genotype collection was evaluated by setting $\Delta \mathrm{K}$ criterion in the STRUCTURE software [31]. The value LnP (K) increased continuously parallel to the increase of $\mathrm{K}$ from 1 to 10 , and there was no obvious inflexion point. The highest $\Delta \mathrm{K}$ value was observed at $\mathrm{K}=2$ in all three analyses (iPBS only, SSR only, and iPBS+SSR) (Figure 8).

The results indicated the existence of two different gene pools or populations for all genotypes (Populations 1 and 2) shown in red and green in Figures 9-11. According to the iPBS data, Population 1 contained 39 fig genotypes (red) and Population 2 consisted of 47 fig genotypes (green), which were randomly distributed within the groups according to location. Both populations included genotypes from Turkey (Izmir and Aydin) and Algeria (Skikda and Mila) (Figure 9). Based on the SSR data, Populations 1 and 2 contained 49 and 37 genotypes, respectively with most of the Algerian genotypes (27 of 33) being grouped under the former (Figure 10). When the iPBS and SSR results were analyzed together, the fig genotypes were grouped according to locations. Population 1 (red) contained most of the Turkish genotypes including \#1 (Morgüz), \#2 (Sultan Selim), \#3 (Cicek inciri), \#4 (Umurbey), \#5 (Kadota2), \#6 (Kadota1), \#7 (Beyaz Cicek),

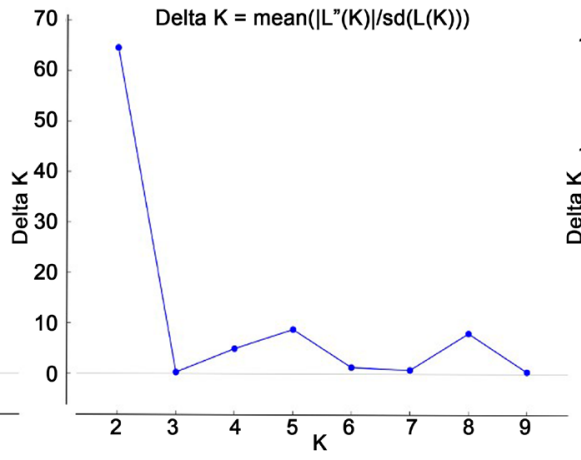

(b) SSR

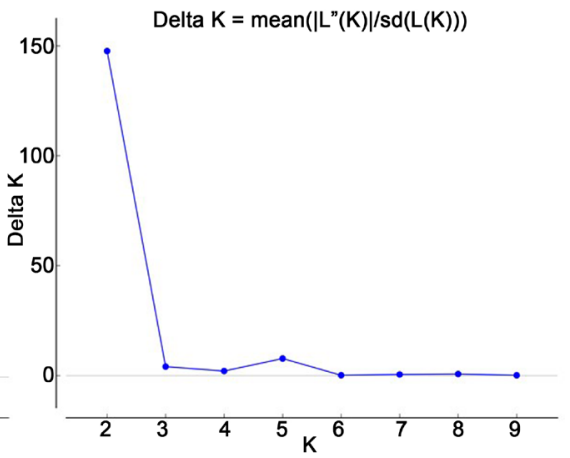

(c) iPBS and SSR

Figure 8. The K value estimated for the structure analysis of fig genotypes based on (a) iPBS data (b) SSR data (c) iPBS + SSR data.
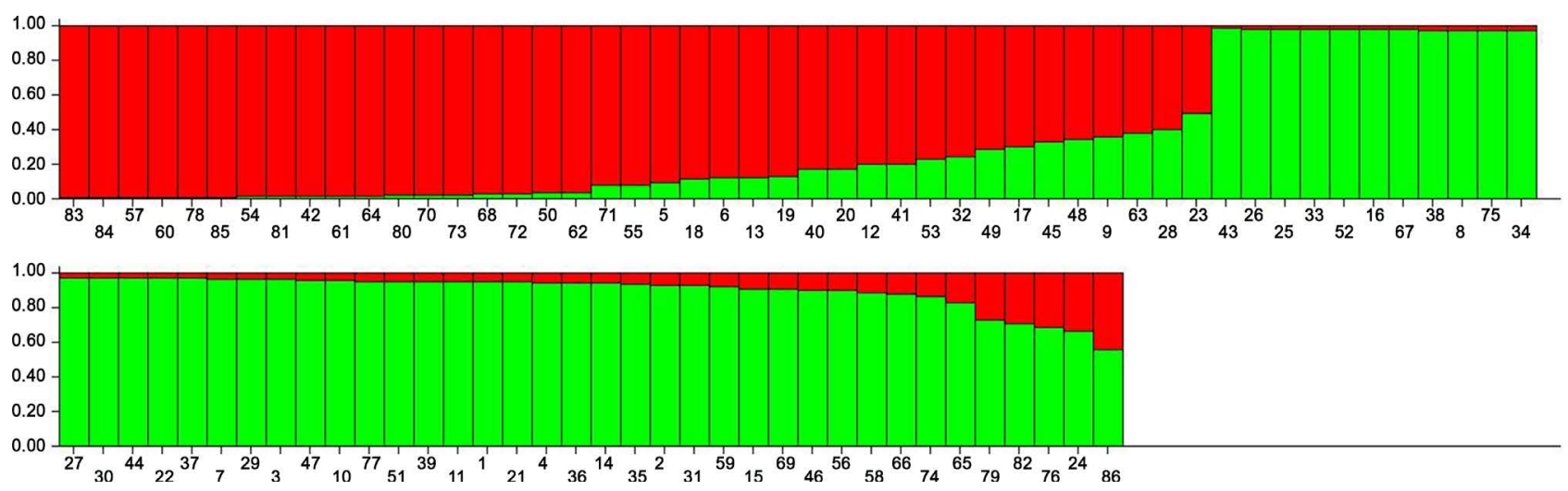

Figure 9. The estimated population structure of fig genotypes using STRUCTURE when $\Delta \mathrm{K}=2$ based on iPBS data (The genotypes are represented by a different color according to the population they belong (Population 1: red, Population 2: green). 


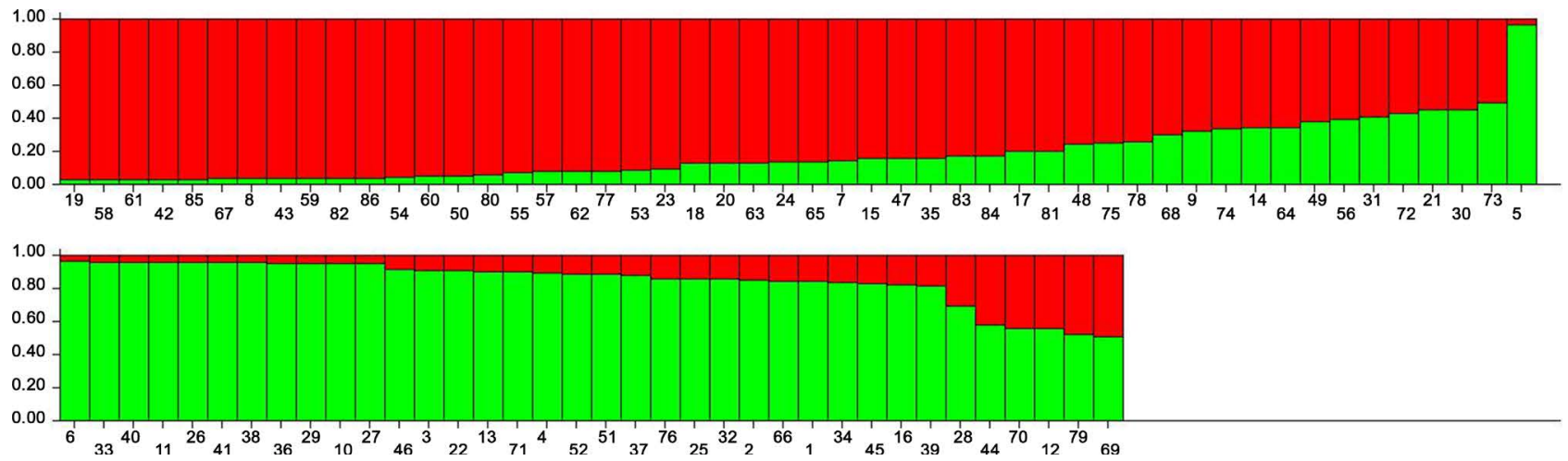

Figure 10. The estimated population structure of fig genotypes using STRUCTURE when $\Delta \mathrm{K}=2$ based on SSR data (The genotypes are represented by a different color according to the population they belong (Population 1: red, Population 2: green).

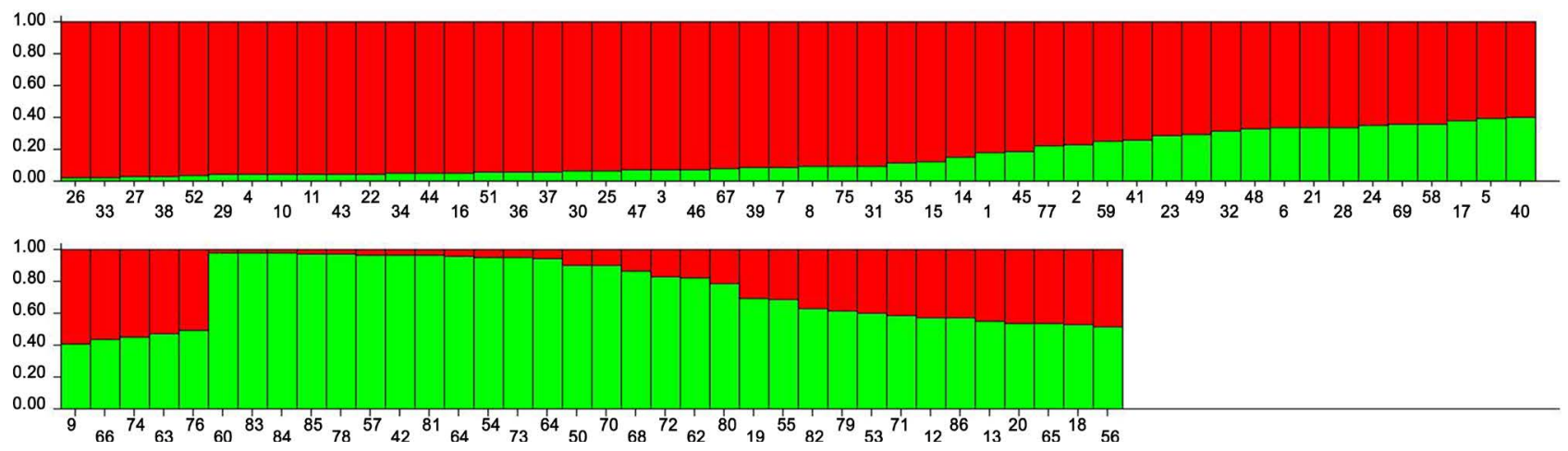

Figure 11. The estimated population structure of fig genotypes using STRUCTURE when $\Delta \mathrm{K}=2$ based on iPBS + SSR data (The genotypes are represented by a different color according to the population they belong (Population 1: red, Population 2: green).

\#8 (Siyah Cicek), \#9 (Siyah İncir), and \#10 (Akca) and Population 2 (green) comprised the majority of the Algerian genotypes; e.g., \#54 (Albo), \#55 (Celeste), \#56 (Cavaliere), \#57 (Boule d'or), \#70 (Taranimt), \#71 (Tameriout), \#72 (Verbale), \#73 (Zreka), \#78 (L’Alebia), and \#79 (Bouzenouna) (Figure 11).

\section{Discussion}

The analysis of the genetic diversity of and relationships between fig genotypes is significant for breeding. The present study proposes a preliminary characterization of Algerian and Turkish fig genotypes collected from different areas of both countries. To the best of our knowledge, this is the first report on the identification and characterization of the F. carica genotypes grown in Algeria and Turkey using the iPBS and SSR markers. We combined all the produced polymorphic bands using both types of molecular markers to provide an insight into the taxonomic image presenting a definite level of taxonomic differentiation [33].

The iPBS-retrotransposon markers can be used as universal markers for the genome of several plants [11]. Recently, the iPBS method has been considered a good molecular marker system since it requires no previous knowledge of the genome and only minimal amount of DNA [34]. Despite these advantages, only few plants have been investigated in terms of their genetic diversity using this 
method [34]. Our study constitutes the first utilization of the iPBS markers for fingerprinting and distinguishing a large number of fig genotypes. In the present study, the iPBS banding pattern of the Ficus genotypes was demonstrated with 63 polymorphic bands of 23 iPBS primers. The average number of the iPBS bands (2.7) was considerably higher than reported by Baránek et al. [15], Guo et al. [17]. And Duan et al [35]. Two of the 12-mer primers (2375 and 2379) generated the lowest number of bands (1 band) while another 12-nt primer (2393) produced the highest number ( 7 bands). For this reason, it was considered that the length of an individual primer (12-nt) did not affect the number of amplified bands, which is in agreement with the results reported by Al-Najm et al. (2016) and Mehmood et al. [18]. The PIC standards were used to evaluate the discriminating aptitude of specific primers and measure the efficiency of polymorphic loci in revealing genetic diversity among the genotypes. The average PIC values of the iPBS primers varied between 0.05 and 0.99 with an average of 0.73 . The average PIC value being greater than 0.5 indicates that iPBS markers can be beneficial for the estimation of the genetic diversity of fig genotypes [36]. These values were considerably higher than those reported for Australian and Iraqi date palm accessions (0.28) [14], China grape accessions (0.445) [17] and Australian guava accessions (PIC: 0.24) [18].

The SSR method also has advantages such as high polymorphism, co-dominance, and reproducibility [37]. In this study, using 16 SSR markers, we observed 25 polymorphic alleles, with an average of 1.56 polymorphic alleles per primer, which was lower than the average values reported by Caliskan et al. [4] (6.8), Aradhya et al. [10] (4.9), Saddoud et al. [38] (6.6), Ikegami et al. [39] (5.2), Perez-Jiménez et al. [40] (3.6), and Ganopoulos et al. [41] (13). One of the disadvantages of using SSR markers is the high cost of designing the primers, which limits the number of species that can be assayed [42]. However, the SSR method requires a large number of primers to detect high polymorphisms. In this study, using the SSR markers, the average PIC value was calculated as 0.67 ranging from 0.95 to 0.16 . The most useful SSR primer was found to be FCUPO66-7, which detected 3 alleles with a PIC of 0.84 . All the genotypes contained a genotype-specific combination of the SSR alleles that allowed their accurate fingerprinting. These PIC values were higher than previously reported by Val et al. [43] (0.56). The PIC value reflects the level of genetic variation in a fig population. It provides a better estimation of diversity than the raw number of alleles because it accounts for the relative frequencies of each allele present. When a marker with a high PIC value is used in diversity studies, the power of discrimination is higher. In this study, the PIC values determined for the iPBS markers were higher compared to the SSR markers. In addition, fewer polymorphic bands were identified using the SSR markers compared to iPBS. Considering that iPBS-retrotransposon is dominant and SSR is co-dominant in nature, the combined use of these markers would have an equal or even higher capacity to reveal polymorphism and offer a greater potential to determine intra- and inter-specific diversity of fig genotypes. 
Concerning genetic dissimilarity, according to all three analyses (iPBS, SSR, and iPBS+SSR), genotypes \#83 (El sefra1) and \#84 (El sefra2) were highly distinct from each other. Furthermore, SSR and iPBS+SSR analyses provided similar results in terms of the most closely related pairs of genotypes; \#50 (506 Beyaz Sultani) and \#57 (Boule d'or), and \#57 (Boule d'or) and \#85 (Biferia). However, the iPBS markers revealed a different pair to have the closest relationship [genotypes \#78 (L'Alebia) and \#83 (El sefra1)]. Since the iPBS and SSR marker systems produced different results in terms of genomic variation and distribution, their combined use would be even more informative and powerful for the identification of fig genotypes. The data indicating high and low genetic diversity can then be used for plant breeding and the improvement of germplasm collections.

The dissimilarity index that was obtained from Nei and Li's dissimilarity coefficient on iPBS and SSR was subjected to a PCA analysis. The contributions of PCA iPBS, PCA SSR, and PCA iPBS-SSR to the total variability were found to be $10.4 \%, 11.8 \%$, and $16.8 \%$, respectively. These values were lower than those reported by Caliskan et al. [4] and Ikten et al. [44]. Figures 5-7 show the distribution of genotypes according to the first two components (PCA 1 and PCA 2).

In the literature, studies on molecular genetic diversity and relationships between genotypes in germplasm collections have mostly utilized multivariate statistical analyses, such as hierarchical cluster analysis, PCA, and model-based clustering algorithms; e.g., the STRUCTURE software. In this study, we chose to use UPGMA clustering analysis, PCA, and STRUCTURE software to compare the results since the combination of these three methods provides a more complete and clear picture of the genetic structure of plants. According to the results of all three analyses using the iPBS and SSR markers, the genotypes were classified into two main groups (Figures 2-11) with only slight differences in terms of the genotypes present. The graphic distribution of the fig genotypes demonstrated that almost all the genotypes were situated independently from their geographic origin. Moreover, the results of the cluster analysis, UPGMA, PCA, and STRUCTURE revealed similar. That is, it has been determined that there are the same variants with different names so-called synonym, except for some genotypes. According to the output of STRUCTURE, genotypes \#17, 21, 44, 45, 46, 48,49 , and 76 were localized in Group 1 (red) while the same genotypes were included in Group 2 (green) according to the UPGMA and PCA results based on the iPBS+SSR data.

According to the iPBS+SSR analysis, the "Soltani" genotypes were included in the same group. Furthermore, the "Sultani" cultivars included genotypes with a different geographic origin, "Soltani” or "Soltania" (\#77) collected from Algeria (Mila), and "403 Sultani" (\#16) collected from Turkey (Aydin) (Figures 2-8). These genotypes having the same variety, but different geographic origins and genetic profiles; therefore, they can be considered homonyms. Similarly, Caliskan et al. [4] reported that "Sultani 2" from Antakya and "Sultani 3" from Yayladagi accessions possessed similar fruit quality characteristics (fruit size, 
shape, skin color, and total soluble solids), and could be the same accessions with different local names. A similar situation is observed for the genotypes " $\mathrm{Ci}$ cek Inciri” (\#3) and "Cicek Inciri” (\#26); "Siyah Incir” (\#9), "216 Siyah İncir” (\#25), and "208 Siyah Incir" (\#29); and "Bursa siyahi” (\#14) and "237 Bursa siyahi” (\#31). This suggests that somatic mutation on a microsatellite locus explains such closely associated genotypes [45]. Moreover, during the historical domestication and cultivation, the extensive diffusion of cultivars resulted in confusion in the classification and identification of cultivars [10]. On the other hand, from the entire collection in the combined iPBS and SSR marker system, there was one wild genotype named "Dhokkar" (86), which is the common word for caprifig in Arabic. Thus, the analysis shows that clustering was independent of botanical types and origin varieties. Although clustering did not indicate any clear division between the fig genotypes based on their geographical origin, the results of iPBS-SSR showed admixtures between individuals and probably shared the same genetic background. These results were in agreement with several studies that used different molecular markers [41] [44] [46] [47] [48] [49]. Moreover, the cluster analysis, UPGMA dendrogram, PCA, and STRUCTURE revealed a single case of synonymy; i.e., "El sefra1" (83) synonymous to "El sefra2" (84), and closely related accessions; "Sultan Selim" (1) and "Cicek Inciri" (2); "Kadota2" (5) and "Kadota1" (6); "Gentille" (66) and "Cavaliere" (56) from the same area as well as "Albo" (54) and "1013 Beyaz Orak" (42) that had a close relationship but were collected from different locations. This similarity between accessions indicates the presence of the same genotypes with different local names.

Overall, the iPBS and SSR markers differed in terms of their nature, information content, and their distribution in the plant genome. IPBS-retrotransposon markers are dominant; therefore, they can detect polymorphisms at several locations within an entire genome whereas SSR markers are co-dominant and detect mutation at particular loci, often within repetitive DNA. This is why the groups generated by two separate analyses contained different genotypes. In fact, every marker shows only a part of the genome in the incongruence of the dendrogram. It was found from these results that the use of multiple markers is extremely crucial in evaluating the relatedness of fig genotypes at the diversity level since different classification results concerning their respective character is the consequence of the use of different markers as reported by Ikegami et al. [39].

This mixture of populations of Mediterranean fruit species is the result of vegetative multiplication, the migration activities of humans, and birds over generations [44]. Furthermore, fig domestication in all the Mediterranean regions has been influenced by human activities [44] [50]. Thus, the fragmentation of tree resources can significantly increase this type of activity [51]. In the current research, a weak genetic structure was observed probably due to the circulating allelic variation across the different fig tree types through a complex pollination mechanism, including the symbiotic relationship between the fig tree and its pollinator and dynamic mutation-recombination operation [41]. These results 
suggest that the genetic diversity in fig genotypes could reflect a high polymorphism in the populations that could indicate a common origin of cultivated fig genotypes in Algeria and Turkey.

The current study presented, for the first time in the literature, the molecular data for the Algerian and Turkish fig genotypes using iPBS and SSR markers. The results confirmed that these two markers are provide valuable information for the molecular characterization of fig genotypes; thus, they can be efficiently used for the identification of a large number of fig genotypes in a time-efficient manner and gaining a deeper understanding of the genetic relationships between these genotypes. The information derived from this research can also be used to increase genetic diversity, establish a reference collection, and determine appropriate breeding and conservation strategies.

\section{Acknowledgements}

The Algerian Ministry of Higher Education and Scientific Research has supported this research and the fellowship of the PhD student (First Author). We would like to thank the National Center for Biotechnology Research, Constantine, Algeria "CRBt" for lyophilized leaves and technical assistance in the laboratory.

\section{References}

[1] Falistocco, E. and Antonielli, L. (2002) Molecular Cytogenetics of Vitis vinifera L. and Ficus carica L.: Location of rDNA sequences. Proceedings of the XLVI Italian Society of Agricultural Genetics, Giardini Naxos, 18-21 September 2002, Poster Abstract 1.19 .

[2] Kislev, M.E., Hartmann, A. and Bar-Yosef, O. (2006) Early Domesticated Fig in the Jordan Valley. Science, 312, 1372-1374. https://doi.org/10.1126/science.1125910

[3] Stover, E., Aradhya, M., Ferguson, L. and Crisosto, C.H. (2007) The Fig: Overview of an Ancient Fruit. HortScience, 42, 1083-1087.

[4] Caliskan, O., Polat, A., Celikkol, P. and Bakir, M. (2012) Molecular Characterization of Autochthonous Turkish Fig Accessions. Spanish Journal of Agricultural Research, 10, 130-140. https://doi.org/10.5424/sjar/2012101-094-11

[5] El-Rayes, R. (1995) The Fig Tree in the Mediterranean Region and in Syria. Options Mediterr, 13, 79-83.

[6] FAOSTAT (2014). http://www.faostat.org

[7] Giraldo, E., Lopez-Corrales, M. and Hormaza, J.I. (2008) Optimization of the Management of an Ex Situ Germplasm Bank in Common Fig with SSRs. Journal of the American Society for Horticultural Science, 133, 69-77.

[8] Khadari, B., Oukabli, A., Ater, M., Mamouni, A., Roger, J. and Kjellberg, F. (2005) Molecular Characterization of Moroccan Fig Germplasm using Intersimple Sequence Repeat and Simple Sequence Repeat Markers to Establish a Reference Collection. Hort Science, 40, 29-32.

[9] Mars, M., Chatti, K., Saddoud, O., Salhi-Hannachi, A., Trifi, M. and Marrakchi, M. (2008) Fig Cultivation and Genetic Resources in Tunisia an Overview. Acta Hort (ISHS), 798, 27-32. https://doi.org/10.17660/ActaHortic.2008.798.2 
[10] Aradhya, M.K., Stover, E., Velasco, D. and Koehmstedt, A. (2010) Genetic Structure and Differentiation in Cultivated Fig (Ficus carica L.). Genetica, 138, 681-694. https://doi.org/10.1007/s10709-010-9442-3

[11] Kalendar, R., Antonius, K., Smýkal, P. and Schulman, A.H. (2010) iPBS: A Universal Method for DNA Fingerprinting and Retrotransposon Isolation. Theoretical and Applied Genetics, 121, 1419-1430. https://doi.org/10.1007/s00122-010-1398-2

[12] Kalendar, R., Flavell, A., Ellis, T., Sjakste, T., Moisy, C. and Schulman, A.H. (2011) Analysis of Plant Diversity with Retrotransposon-Based Molecular Markers. Heredity, 106, 520-530. https://doi.org/10.1038/hdy.2010.93

[13] Smýkal, P., Bačová-Kerteszová, N., Kalendar, R., Corander, J., Schulman, A.H. and Pavelek, M. (2011) Genetic Diversity of Cultivated Flax (Linum usitatissimum L.) Germplasm Assessed by Retrotransposon-Based Markers. Theoretical and Applied Genetics, 122, 1385-1397. https://doi.org/10.1007/s00122-011-1539-2

[14] Al-Najm, A., Luo, S., Ahmad, N.M. and Trethowan, R. (2016) Molecular Variability and Genetic Relationships of Date Palm (Phoenix dactylifera L.) Cultivars Based on Inter-Primer Binding Site (iPBS) Markers. Australian Journal of Crop Science, 10, 732-740. https://doi.org/10.21475/ajcs.2016.10.05.p7491

[15] Baránek, M., Meszáros, M., Sochorová, J., Čechová, J. and Raddová, J. (2012) Utility of Retrotransposon-Derived Marker Systems for Differentiation of Presumed Clones of the Apricot Cultivar Velkopavlovická. Scientia Horticulturae, 143, 1-6. https://doi.org/10.1016/j.scienta.2012.05.022

[16] Fang-Yong, C. and Ji-Hong, L. (2014) Germplasm Genetic Diversity of Myrica rubra in Zhejiang Province Studied using Inter-Primer Binding Site and Start Codon-Targeted Polymorphism Markers. Scientia Horticulture, 170, 169-175. https://doi.org/10.1016/j.scienta.2014.03.010

[17] Guo, D.L., Guo, M.X., Hou, X.G. and Zhang, G.H. (2014) Molecular Diversity Analysis of Grape Varieties Based on iPBS Markers. Biochemical Systematics and Ecology, 52, 27-32. https://doi.org/10.1016/j.bse.2013.10.008

[18] Mehmood, A., Jaskani, M.J., Ahmad, S. and Ahmad, R. (2013) Evaluation of Genetic Diversity in Open Pollinated Guava by iPBS Primers. Pakistan Journal of Agricultural Sciences, 50, 591-597.

[19] Raddová, J., Ptáčková, H., Čechová, J. and Ondrášek, I. (2013) Genetic Analysis of the Genus Diospyros ssp. using RAPD and iPBS Methods. Acta Universitatis Agriculturae et Silviculturae Mendelianae Brunensis, 60, 205-216. https://doi.org/10.11118/actaun201260080205

[20] Healey, A., Furtado, A., Cooper, T. and Henry, R.J. (2014) Protocol: A Simple Method for Extracting Next-Generation Sequencing Quality Genomic DNA from Recalcitrant Plant Species. Plant Methods, 10, 1. https://doi.org/10.1186/1746-4811-10-21

[21] Khadari, B., Hochu, I., Santoni, S. and Kjellberg, F. (2001) Identification and Characterization of Microsatellite Loci in the Common Fig (Ficus carica L.) and Representative Species of the Genus Ficus. Molecular Ecology Notes, 1, 191-193. https://doi.org/10.1046/j.1471-8278.2001.00072.x

[22] Giraldo, E., Viruel, M., López-Corrales, M. and Hormaza, J. (2005) Characterisation and Cross-Species Transferability of Microsatellites in the Common Fig (Ficus carica L.). The Journal of Horticultural Science and Biotechnology, 80, 217-224. https://doi.org/10.1080/14620316.2005.11511920 
[23] Zavodna, M., Arens, P., Van Dijk, P.J. and Vosman, B. (2005) Development and Characterization of Microsatellite Markers for Two Dioecious Ficus Species. Molecular Ecology Notes, 5, 355-363. https://doi.org/10.1111/j.1471-8286.2005.00924.x

[24] Ahmed, S., Dawson, D.A., Compton, S.G. and Gilmartin, P.M. (2007) Characterization of Microsatellite Loci in the African Fig Ficus sycomorus L. (Moraceae). Molecular Ecology Notes, 7, 1175-1177. https://doi.org/10.1111/j.1471-8286.2007.01822.x

[25] Bandelj, D., Javornik, B. and Jakse, J. (2007) Development of Microsatellite Markers in the Common Fig Ficus carica L. Molecular Ecology Notes, 7, 1311-1314. https://doi.org/10.1111/j.1471-8286.2007.01866.x

[26] Anderson, J.A., Churchill, G., Autrique, J., Tanksley, S. and Sorrells, M. (1993) Optimizing Parental Selection for Genetic Linkage Maps. Genome, 36, 181-186. https://doi.org/10.1139/g93-024

[27] Botstein, D., White, R.L., Skolnick, M. and Davis, R.W. (1980) Construction of a Genetic Linkage Map in Man using Restriction Fragment Length Polymorphisms. American Journal of Human Genetics, 32, 314.

[28] Rohlf, F.J. (1988) NTSYS-pc Numerical Taxonomy and Multivariate Analysis System. Exeter Publishing Ltd., New York.

[29] Tamura, K., Stecher, G., Peterson, D., Filipski A. and Kumar, S. (2013) MEGA6: Molecular Evolutionary Genetics Analysis Version 6.0. Molecular Biology and Evolution, 30, 2725-2729. https://doi.org/10.1093/molbev/mst197

[30] Pritchard, J.K., Stephens, M. and Donnelly, P. (2000) Inference of Population Structure using Multilocus Genotype Data. Genetics, 155, 945-959.

[31] Evanno, G., Regnaut, S. and Goudet, J. (2005) Detecting the Number of Clusters of Individuals using the Software STRUCTURE: A Simulation Study. Molecular Ecology, 14, 2611-2620. https://doi.org/10.1111/j.1365-294X.2005.02553.x

[32] Earl, D. and Von Holdt, B. (2011) Structure Harvester: A Website and Program for Visualizing STRUCTURE Output and Implementing the Evanno Method. Conservation Genetics Resources, 4, 359-361.

[33] Sneller, C., Miles, J. and Hoyt, J. (1997) Agronomic Performance of Soybean Plant Introductions and Their Genetic Similarity to Elite Lines. Crop Science, 37, 1595-1600. https://doi.org/10.2135/cropsci1997.0011183X003700050032x

[34] Odong, T., Van Heerwaarden, J., Jansen, J., Van Hintum, T.J. and Van, E.F. (2011) Determination of Genetic Structure of Germplasm Collections: Are Traditional Hierarchical Clustering Methods Appropriate for Molecular Marker Data. Theoretical and Applied Genetics, 123, 195-205. https://doi.org/10.1007/s00122-011-1576-x

[35] Duan, Y., Guo, D., Guo, L., Wei, D. and Hou, X. (2015) Genetic Diversity Analysis of Tree Peony Germplasm using iPBS Markers. Genetics and Molecular Research, 14, 7556-7566. https://doi.org/10.4238/2015.July.3.31

[36] De Riek, J., Calsyn, E., Everaert, I., Van Bockstaele, E. and De Loose, M. (2001) AFLP Based Alternatives for the Assessment of Distinctness Uniformity and Stability of Sugar Beet Varieties. Theoretical and Applied Genetics, 103, 1254-1265. https://doi.org/10.1007/s001220100710

[37] Wuensch, A. (2009) Cross-Transferable Polymorphic SSR Loci in Prunus Species. Scientia Horticulturae, 120, 348-352. https://doi.org/10.1016/j.scienta.2008.11.012

[38] Saddoud, O., Salhi-Hannachi, A., Chatti, K., Rhouma, A., Mars, M., Marrakchi, M. and Trifi, M. (2005) Tunisian Fig (Ficus carica L.) Genetic Diversity and Cultivars Identification Mediated by Microsatellites Markers. Fruits, 60, 143-153. https://doi.org/10.1051/fruits:2005018 
[39] Ikegami, H., Nogata, H., Hirashima, K., Awamura, M. and Nakahara, T. (2009) Analysis of Genetic Diversity among European and Asian Fig Varieties (Ficus carica L.) using ISSR RAPD and SSR Markers. Genetic Resources and Crop Evolution, 56, 201-209. https://doi.org/10.1007/s10722-008-9355-5

[40] Perez Jiménez, M., López, B., Dorado, G., Pujadas Salvá, A., Guzmán, G. and Hernandez, P. (2012) Analysis of Genetic Diversity of Southern Spain Fig Tree (Ficus carica L.) and Reference Materials as a Tool for Breeding and Conservation. Hereditas, 149, 108-113. https://doi.org/10.1111/j.1601-5223.2012.02154.x

[41] Ganopoulos, I., Xanthopoulou, A., Molassiotis, A., Karagiannis, E., Moysiadis, T., Katsaris, P., Aravanopoulos, F., Tsaftaris, A., Kalivas, A. and Madesis, P. (2015) Mediterranean Basin Ficus carica L.: From Genetic Diversity and Structure to $\mathrm{Au}-$ thentication of a Protected Designation of Origin Cultivar using Microsatellite Markers. Trees, 29, 1959-1971. https://doi.org/10.1007/s00468-015-1276-2

[42] Dayanandan, S., Bawa, K.S. and Kesseli, R. (1997) Conservation of Microsatellites among Tropical Trees (Leguminosae). American Journal of Botany, 84, 1658-1663. https://doi.org/10.2307/2446463

[43] Do Val, A., Souza, C., Ferreira, E., Salgado, S., Pasqual, M. and Cancado, G. (2013) Evaluation of Genetic Diversity in Fig Accessions by using Microsatellite Markers. Genetics and Molecular Research, 12, 1383-1391. https://doi.org/10.4238/2013.April.25.9

[44] Ikten, H., Mutlu, N., Gulsen, O., Kocatas, H. and Aksoy, U. (2010) Elucidating Genetic Relationships Diversity and Population Structure among the Turkish Female Figs. Genetica, 138, 169-177. https://doi.org/10.1007/s10709-009-9400-0

[45] Achtak, H., Oukabli, A., Ater, M., Santoni, S., Kjellberg, F. and Khadari, B. (2009) Microsatellite Markers as Reliable Tools for Fig Cultivar Identification. Journal of the American Society for Horticultural Science, 134, 624-631.

[46] Baraket, G., Chatti, K., Saddoud, O., Abdelkarim, A.B., Mars, M., Trifi, M. and Hannachi, A.S. (2011) Comparative Assessment of SSR and AFLP Markers for Evaluation of Genetic Diversity and Conservation of Fig Ficus carica L, Genetic Resources in Tunisia. Plant Molecular Biology Reporter, 29, 171-184. https://doi.org/10.1007/s11105-010-0217-x

[47] Baraket, G., Chatti, K., Saddoud, O., Mars, M., Marrakchi, M., Trifi, M. and Salhi-Hannachi, A. (2009) Genetic Analysis of Tunisian Fig (Ficus carica L.) Cultivars using Amplified Fragment Length Polymorphism (AFLP) Markers. Scientia Horticulturae, 120, 487-492. https://doi.org/10.1016/j.scienta.2008.12.012

[48] Chatti, K., Saddoud, O., Salhi-Hannachi, A., Mars, M., Marrakchi, M. and Trifi, M. (2007) Analysis of Genetic Diversity and Relationships in a Tunisian Fig (Ficus carica) Germplasm Collection by Random Amplified Microsatellite Polymorphisms. Journal of Integrative Plant Biology, 49, 386-391. https://doi.org/10.1111/j.1744-7909.2007.00396.x

[49] Salhi-Hannachi, A., Chatti, K., Saddoud, O., Mars, M., Rhouma, A., Marrakchi, M. and Trifi, M. (2006) Genetic Diversity of Different Tunisian Fig (Ficus carica L.) Collections Revealed by RAPD Fingerprints. Hereditas, 143, 15-22. https://doi.org/10.1111/j.2005.0018-0661.01904.x

[50] Khadari, B., Grout, C., Santoni, S. and Kjellberg, F. (2005) Contrasted Genetic Diversity and Differentiation among Mediterranean Populations of Ficus carica L.: A Study using mtDNA RFLP. Genetic Resources and Crop Evolution, 52, 97-109. https://doi.org/10.1007/s10722-005-0290-4 
[51] Andrianoelina, O., Rakotondraoelina, H., Ramamonjisoa, L., Maley, J., Danthu, P. and Bouvet, J.M. (2006) Genetic Diversity of Dalbergia monticola (Fabaceae) an Endangered Tree Species in the Fragmented Oriental Forest of Madagascar. In: Forest Diversity and Management, Springer, Berlin, 49-68.

https://doi.org/10.1007/978-1-4020-5208-8_4 